\title{
La Investigación Científica en la Universidad Peruana
}

El análisis de la situación de las universidades en investigación, obliga a una reflexión previa al considerar la heterogeneidad que subyace bajo el concepto de calidad en la educación universitaria, por ello es importante destacar las marcadas diferencias que existe entre ellas, incluso entre unidades académicas internas de una misma universidad, esta heterogeneidad engloba diversos problemas, tal como afirmaba Mabres (1994) al considerar como los problemas más importantes; el bajo nivel académico, incertidumbre económica, escasa relación con el sector empresarial, poca colaboración entre universidades y escasa investigación de calidad, aún parecen estar presentes en la actualidad. Los esfuerzos por encausar el proceso de recuperación se han dado bajo las condiciones dispuestas por el estado a través de la Superintendencia Nacional de Educación Superior Universitaria (SUNEDU) mediante ley 30220 que promueve el mejoramiento continuo de la calidad educativa de las instituciones universitarias como entes fundamentales del desarrollo nacional, de la investigación y de la cultura; poniendo freno a la proliferación de universidades y poner reglas para mejorar la calidad de la enseñanza, los procesos de investigación y producción intelectual, no obstante para que este último punto sea eficiente y maduro, necesita de un apoyo estatal decidido, porque todas las buenas intenciones se traducen en disponer de los recursos económicos necesarios.

Respecto a la producción científica en la universidad peruana, se presentan grandes desafíos en la búsqueda de alcanzar estándares mínimos que permitan ubicarse en los rankings mundiales de investigación científica, ya que en la actualidad ninguna universidad latinoamericana destaca dentro de los 100 mejores del mundo, además que en Latinoamérica el Perú ocupa los últimos lugares (Sánchez, 2016). Esta realidad indica que el camino se muestra con una pendiente tortuosa, porque existen muchos problemas que resolver como la exigua capacidad instalada, recursos exiguos, docentes escasamente capacitados para encausar investigaciones de impacto, además de vallas muy altas fijadas por los organismos acreditadores que en muchos casos son inadecuados con nuestra realidad que dificulta alcanzar los estándares. Esta realidad hacía notar el año 2018, que el Perú estaba ubicado en el ranking global de disponibilidad de científicos en el puesto 113 de 148. Todo ello refleja la debilidad del país para poder afrontar temas de creación de conocimiento e innovación (Grados, 2018). 
A manera de conclusión; Todos los esfuerzos son difusos, si no existe una dotación de logística y recursos necesarios para hacer producción científica de calidad, y que todo lo normado no procura por si sola lograr los estándares de calidad en la producción científica en la universidad peruana.

Dr. Arcadio Atencio Vargas

Director revista Ingeniería Investiga Decano Facultad Ingeniería - UPT

\section{Bibliografía consultada}

Alhuay Quispe, J., \& Pacheco Mendoza, J. (2018). Escaso uso de indicadores de productividad científica en estudios bibliométricos. In Educación Médica. Elsevier España.

Grados Pomarino, S. (2018). Problemática de la investigación científica universitaria en el Perú. Odontol. Sanmarquina.

Mabres, A. (1994). Problemas y perspectivas de las universidades peruanas.

Sánchez Carlessi, H. H. (2016). Desafíos para la Investigación en la Universidad Peruana. 